\title{
The association of higher levels of within-normal-limits liver enzymes and the prevalence of the metabolic syndrome
}

\author{
Arie Steinvil ${ }^{+1}$, Itzhak Shapira ${ }^{\dagger 1}$, Orit Kliuk Ben-Bassat ${ }^{1}$, Michael Cohen ${ }^{1}$, Yaffa Vered ${ }^{2}$, Shlomo Berliner ${ }^{1}$ and \\ Ori Rogowski*1
}

\begin{abstract}
Background: Metabolic syndrome (MetS) is frequently characterized by elevated liver enzymes, including gammaglutamyl transferase (GGT) and alanine aminotransferase (ALT). Our objective was to evaluate the range of prevalence of MetS in apparently healthy individuals whose liver enzyme concentrations were all within-normal-range.

Methods: We have performed a cross sectional analysis on participants of the Tel-Aviv medical center inflammation survey (TAMCIS) recruited between the years 2003-2009. Analyzed were a cohort of 6,561 men and 3,389 women.

Results: The prevalence of MetS increased significantly from the first quintile to the fifth for both GGT and ALT, all the five quintiles being in the normal range. Logistic regression analysis for the presence of MetS showed crude odds ratios of 2.7 and 2.4 between the first and fourth quintiles and 3.6 and 3.2 for the fifth quintile in men and women respectively for ALT. For GGT the respective odds being 3.6 and 3.2 for the fourth quintile and 3.9 and 3.4 for the fifth quintile in men and women, respectively.

Conclusions: A relatively high prevalence of MetS was noted in a cohort of apparently healthy individuals with liver enzyme concentrations within-normal-limits. Practical consequences include the need to follow up these enzyme concentrations as continuous variables and to take into consideration that even relatively small elevations within the normal range might reflect the presence of dysmetabolism.
\end{abstract}

\section{Background}

The metabolic syndrome (MetS) is a constellation of cardiovascular risk factors known to be associated with increased future atherothrombotic events [1-4]. Previous studies have shown that elevated liver enzymes concentrations were associated with the diagnosis of MetS and of its components [5-9].

Little is known however, about the association between the prevalence of the metabolic syndrome among individuals presenting with within-normal-range liver enzymes. To the best of our knowledge, there is only one paper which demonstrated that even 'normal' levels of ALT are associated with the long-term development of

\footnotetext{
* Correspondence: orir@tasmc.health.gov.l

1 Departments of Medicine "D" \& "E", The Tel-Aviv Sourasky Medical Center, 6

Weizman St, Tel Aviv, 64239, Israel

+ Contributed equally

Full list of author information is available at the end of the article
}

multiple metabolic disorders, including the MetS and diabetes mellitus [10].

Since both elevated GGT [11-18] and ALT [19-22] have demonstrated significant associations with both atherothrombotic burden and vascular risk, we have performed a cross sectional analysis to evaluate the prevalence of the MetS in a relatively large sample of apparently healthy individuals in whom both GGT and ALT as well as aspartate aminotransferase (AST) were all within the normal limits.

\section{Methods}

\section{Study population}

We have presently analyzed data that has been collected during the last five years in the Tel-Aviv medical center inflammation survey (TAMCIS), a registered data bank of the Israeli ministry of justice [23-29]. This is a relatively large cohort of individuals who attended our medical 
center for a routine annual check-up and who gave their written informed consent for participation according to the instructions of the institutional ethics committee. A total of 16,413 subjects gave their informed consent (10,389 males, 6,024 females). Later, 2,071 subjects were excluded from the analysis due to any malignancy or immunosuppressive therapy, pregnancy, steroidal or antibiotic treatment or recent acute infection. We further excluded 927 individuals due to diabetes mellitus and 221 individuals for reporting regular alcohol use of more than 1 glass per day. Finally, an additional 1,241 subjects were excluded for missing data on any of their liver function enzyme measurements and 2,003 individuals with any of the three liver function enzymes concentrations that we routinely check (ALT, GGT and AST) in whom these levels were found to be above the upper limit of normal according to our local laboratory. Following these exclusions the study group comprised 9,950 individuals $(6,561$ men and 3,389 women).

\section{Definitions of atherothrombotic risk factors}

Results of the routine health check-up were assessed employing certain definitions in order to recognize atherothrombotic risk factors in individuals. These included diabetes mellitus which was defined as a fasting blood glucose concentration of $\geq 7.0 \mathrm{mmol} / \mathrm{L}$ or the intake of insulin or oral hypoglycemic medications. Hypertension was defined as a blood pressure of $\geq 140 / 90 \mathrm{~mm} \mathrm{Hg}$ on two separate measurements or the use of antihypertensive medications. Dyslipidemia was defined as the low density lipoprotein cholesterol (LDL-C) or non-high density lipoprotein cholesterol (non-HDL-C) concentrations, for individuals displaying elevated triglyceride concentrations of $>2.26 \mathrm{mmol} / \mathrm{L}$, above the recommended levels according to the risk profile defined by the updated adult treatment panel III (ATP III) recommendations [30] or the use of lipid lowering medications. The diagnosis of the metabolic syndrome was based on the joint interim statement of the International Diabetes Federation Task Force on Epidemiology and Prevention; National Heart, Lung, and Blood Institute; American Heart Association; World Heart Federation; International Atherosclerosis Society; and International Association for the Study of Obesity [31]. In short, elevated waist circumference was defined as $\geq 94 \mathrm{~cm}$ (37 inches) in men and $\geq 80$ (31.5 inches) in women as recommended for europid and middle east; elevated triglycerides (TG) were defined as $\geq 150$ $\mathrm{mg} / \mathrm{dl}(1.7 \mathrm{mmol} / \mathrm{l})$ or on drug treatment for elevated triglycerides; reduced HDL-C was defined as $<40 \mathrm{mg} / \mathrm{dL}$ $(1.0 \mathrm{mmol} / \mathrm{l})$ in men and $<50 \mathrm{mg} / \mathrm{dl}(1.3 \mathrm{mmol} / \mathrm{l})$ in women or on drug treatment for reduced HDL-C; elevated blood pressure was defined as $\geq 130 \mathrm{~mm} \mathrm{Hg}$ systolic blood pressure or $\geq 85 \mathrm{~mm} \mathrm{Hg}$ diastolic blood pressure or on antihypertensive drug treatment in a patient with a history of hypertension; elevated fasting glucose was defined as $\geq 100 \mathrm{mg} / \mathrm{dl}(5.55 \mathrm{mmol} / \mathrm{l})$. Smokers were defined as individuals who smoked at least 5 cigarettes per day while past smokers had quit smoking for at least 30 days prior to examination.

\section{Laboratory methods}

All blood samples were drawn following a 12 hour fasting period. Glucose was measured by the glucose oxidase system [32]. We utilized an improved color reagent for the determination of blood glucose by the oxidase system using the Bayer Advia 1650 chemistry analyzer. Triglycerides were measured by an adaptation of the Fossati 3 step enzymatic reaction with the Bayer Advia 1650 chemistry analyzer. Serum triglycerides were determined calorimetrically with an enzyme that produces hydrogen peroxide[33]. HDL-C was determined by the method developed by Izawa et al [34] using the Bayer Advia 1650 chemistry analyzer. LDL-C was derived from the measured concentrations of total cholesterol, HDL-C and triglycerides using the Friedwald equation: LDL-C = Total Cholesterol - HDL-C - TG/5. GGT was determined by the method of Szasz [35] using the Bayer Advia 1650 chemistry analyzer. ALT was determined by the modified method in accordance with the International Federation of Clinical Chemistry (IFCC) [36] using the Bayer Advia 1650 chemistry analyzer.

\section{Statistical analysis}

All data was summarized and displayed as mean (standard deviation $[\mathrm{SD}]$ ) for the continuous variables and as number of patients (expressed as a percentage) in each group for the categorical variables. Since the triglyceride concentrations displayed irregular distributions, we used logarithmic transformation which converted the distributions to normal ones for all statistical procedures. Therefore all results of triglyceride concentrations are expressed as back-transformed geometrical means. The One-Way Kolmogorov-Smirnov test was used to assess the distributions. In order to characterize the population we divided the patients in each gender into quintiles of each of the two liver function enzymes of relevance, including GGT and ALT, and analyzed all results accordingly. For all categorical variables the Chi-square statistical test was used for assessing the statistical significance between the quintiles, while the One-Way Analysis of Variance was used for all continuous variables. In order to better appreciate the magnitude of the differences in the prevalence of the MetS between the quintiles of the liver enzymes and in order to adjust for differences in age, physical activity, smoking status and use of medications that are not a part of the parameters which define the MetS, we used logistic regression and calculated the odds ratio for having the MetS between the quintiles of each 
liver enzyme relative to the lower quintile. All above analyses were considered significant at $\mathrm{p}<0.05$ (two tailed). The SPSS statistical package was used to perform all statistical evaluations (SSPS Inc., Chicago, IL, USA).

\section{Results}

We have presently analyzed the results of a total of 6,561 men and 3,389 women at the mean (SD) age of 44 (11) years. Nine hundred and sixteen men (14\%) and 645 women (19\%) were characterized as having the metabolic syndrome. Epidemiological data as well as relevant biochemistry for men and women are given in Tables 1 and 2 for ALT and GGT, respectively. In Tables 3 and 4 we report the results of the logistic regression analyses for the presence of the MetS in relation to the quintiles of ALT and GGT, respectively. It can be seen that for ALT, the crude odds ratios increase up to 2.7 and 2.4 in the fourth quintile and even 3.6 and 3.2 for the fifth quintile for both men and women. The respective odds ratios for GGT being 3.6 and 3.2 in the fourth quintile and 3.9 and 3.4 for the fifth. The percentages of individuals with the MetS according to quintiles of each of the within-normallimits liver enzyme concentrations are reported in Figure 1 for both men and women. Tables $3 \& 4$ also evaluate the adjusted odds ratios after adjustment for several relevant parameters that are not a direct part of the definition of the MetS. Those parameters include age, exercise intensity, use of aspirin and statins, smoking status and alcohol consumption. We further adjusted our models to obesity and the results did not change significantly following all those adjustments. Finally, in order to decrease the influence of possible confounders, we have repeated this analysis by further excluding subjects receiving statins, fibrates, amiodarone as well as women taking oral contraceptives or hormonal replacement therapy and the results were not changed significantly (data not shown).

\section{Discussion}

We have presently shown that the MetS is prevalent in individuals who present normal concentrations of liver enzymes. Special attention has been given to two of them (GGT and ALT) for whom epidemiological evidence suggests an association with increased vascular risk. Goessling et al [10] have recently studied the relationship between aminotransferase levels and the incidence of MetS, DM, cardiovascular disease and all cause mortality in long-term follow-up of 2812 participants in the community-based Framingham Heart Study sample. They demonstrated a clear association between elevated ALT levels and the development of MetS and DM over 20 years of follow-up. They also found that ALT levels within the normal range are associated with adverse metabolic outcomes [10].

In our study, we found that the prevalence of the MetS doubles if a comparison is made between the first, second and third quintiles of both GGT and ALT. In these quintiles the concentrations of the enzymes are not only regarded as being absolutely normal, but are actually even in the lower range of the "normal" values. Assuming a link between these enzymes and a potential dysmetabolic state, the finding might suggest a relatively high sensitivity of these biomarkers to reveal the presence of dysmetabolism.

Elevated liver enzymes are well documented in individuals with the MetS and are markers of fatty liver changes [37]. To a certain degree these changes can be visualized by the use of ultrasonography but this procedure is not cost effective and lacks sufficient sensitivity and specificity on a population level in screening apparently healthy individuals with within-normal-limits concentrations of liver enzymes. It would certainly not normally be performed in asymptomatic individuals whose liver enzymes are in the lower part of the so-called normal range and, if
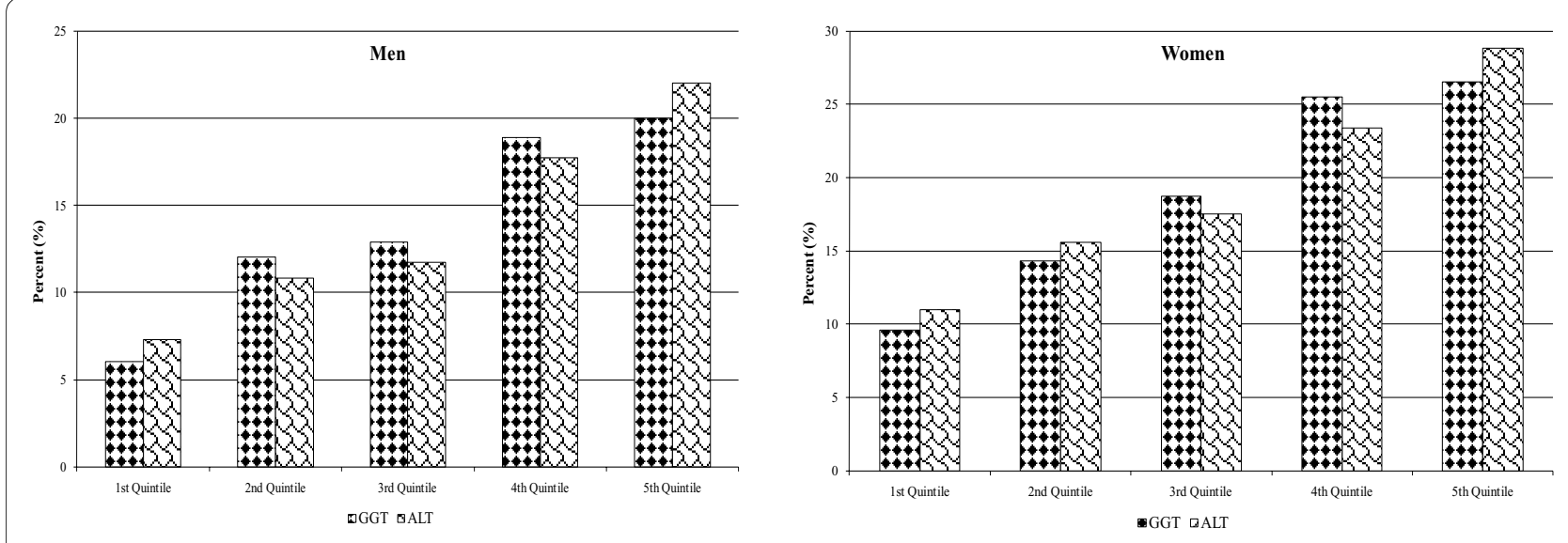

Figure 1 Percentages of individuals with the metabolic syndrome (men and women) according to quintiles of each of the within-normallimits liver enzyme concentrations (ALT, alanine aminotransferase; GGT, gamma-glutamyl transferase) 
Table 1: Patient characteristics* according to quintiles of ALT

\begin{tabular}{|c|c|c|c|c|c|c|c|c|c|c|c|c|}
\hline \multirow[t]{3}{*}{ Men $(\mathrm{N}=6561)$} & \multicolumn{2}{|c|}{$1^{\text {st }}$ Quintile } & \multicolumn{2}{|c|}{ 2nd Quintile } & \multicolumn{2}{|c|}{$3^{\text {rd }}$ Quintile } & \multicolumn{2}{|c|}{$4^{\text {th }}$ Quintile } & \multicolumn{2}{|c|}{$5^{\text {th }}$ Quintile } & \multirow[t]{2}{*}{ ANOVA $/ \mathrm{X}^{2}$} & \multirow{3}{*}{$\begin{array}{l}\mathrm{P} \text { for linear } \\
\text { trend }\end{array}$} \\
\hline & \multicolumn{2}{|c|}{$A L T<16$} & \multicolumn{2}{|c|}{$16 \leq \mathrm{ALT}<20$} & \multicolumn{2}{|c|}{$20 \leq A L T<23$} & \multicolumn{2}{|c|}{$23 \leq A L T<29$} & \multicolumn{2}{|c|}{$29 \leq A L T \leq 40$} & & \\
\hline & & 196 & & 545 & & 121 & & 460 & \multicolumn{2}{|c|}{1239} & P Value & \\
\hline Age (years) & & (11) & 44 & $(11)$ & 44 & (11) & 44 & (11) & 44 & (11) & 0.757 & 0.280 \\
\hline Waist (cm) & 94 & (10) & 95 & $(11)$ & 95 & (11) & 95 & (10) & 95 & (10) & 0.299 & 0.032 \\
\hline $\mathrm{BMI}\left(\mathrm{kg} / \mathrm{m}^{2}\right)$ & 27 & (4) & 27 & (4) & 27 & (4) & 27 & (4) & 27 & (4) & 0.084 & 0.017 \\
\hline Diastolic BP (mmHg) & 78 & (9) & 78 & (8) & 78 & (8) & 78 & (9) & 79 & (8) & 0.206 & 0.025 \\
\hline Systolic BP (mmHg) & 125 & (15) & 124 & (14) & 124 & (15) & 124 & (15) & 125 & (14) & 0.603 & 0.865 \\
\hline Alcohol consumption (glasses/week) & 1.0 & $(1.5)$ & 1.1 & $(1.6)$ & 1.1 & $(1.5)$ & 1.1 & $(1.6)$ & 0.9 & $(1.5)$ & 0.132 & 0.189 \\
\hline Exercise intensity (hours/week) & 2.4 & (3.0) & 2.3 & $(2.7)$ & 2.2 & $(2.5)$ & 2.3 & $(2.9)$ & 2.2 & $(2.5)$ & 0.274 & 0.102 \\
\hline Smoking status, n (\%) & & & & & & & & & & & 0.685 & \\
\hline Current & 184 & $(15.7)$ & 256 & $(17.0)$ & 177 & $(16.0)$ & 215 & $(15.0)$ & 207 & $(17.1)$ & & \\
\hline Former & 292 & (24.9) & 396 & $(26.2)$ & 286 & (25.9) & 388 & $(27.1)$ & 328 & $(27.1)$ & & \\
\hline Hypertension, n (\%) & 286 & $(23.9)$ & 362 & $(23.4)$ & 298 & (26.6) & 340 & $(23.3)$ & 328 & $(26.5)$ & 0.111 & \\
\hline Anti-hypertensive medications, n(\%) & 100 & (8.4) & 145 & $(9.4)$ & 118 & $(10.5)$ & 133 & $(9.1)$ & 135 & $(10.9)$ & 0.192 & \\
\hline Metabolic Syndrome, n (\%) & 87 & $(7.3)$ & 167 & $(10.8)$ & 131 & (11.7) & 258 & (17.7) & 273 & $(22.0)$ & $<0.001$ & \\
\hline Glucose (mmol/L) & 4.86 & $(0.45)$ & 4.99 & $(0.50)$ & 5.07 & $(0.52)$ & 5.13 & $(0.53)$ & 5.19 & $(0.55)$ & $<0.001$ & $<0.001$ \\
\hline HDL Cholesterol (mmol/L) & 1.57 & $(0.39)$ & 1.50 & $(0.37)$ & 1.46 & $(0.36)$ & 1.39 & $(0.33)$ & 1.34 & $(0.31)$ & $<0.001$ & $<0.001$ \\
\hline LDL Cholesterol (mmol/L) & 2.90 & $(0.81)$ & 3.07 & $(0.82)$ & 3.11 & $(0.80)$ & 3.20 & $(0.82)$ & 3.21 & $(0.80)$ & $<0.001$ & $<0.001$ \\
\hline Triglycerides $^{\dagger}(\mathrm{mmol} / \mathrm{L})$ & 0.95 & & 1.00 & & 1.09 & & 1.21 & & 1.35 & & $<0.001$ & $<0.001$ \\
\hline Statins, $n(\%)$ & 117 & $(9.8)$ & 142 & $(9.2)$ & 97 & (8.7) & 129 & $(8.8)$ & 124 & $(10.0)$ & 0.732 & \\
\hline Fibrates, n(\%) & 14 & $(1.2)$ & 19 & $(1.2)$ & 11 & $(1.0)$ & 12 & $(0.8)$ & 10 & $(0.8)$ & 0.718 & \\
\hline \multirow[t]{2}{*}{ Women ( $N=3389$ ) } & \multicolumn{2}{|c|}{$1^{\text {st }}$ Quintile } & \multicolumn{2}{|c|}{$2^{\text {nd }}$ Quintile } & \multicolumn{2}{|c|}{$3^{\text {rd }}$ Quintile } & \multicolumn{2}{|c|}{$4^{\text {th }}$ Quintile } & \multicolumn{2}{|c|}{$5^{\text {th }}$ Quintile } & ANOVA & $\begin{array}{l}\text { P for linear } \\
\text { trend }\end{array}$ \\
\hline & \multicolumn{2}{|c|}{ ALT $<16$} & \multicolumn{2}{|c|}{$16 \leq \mathrm{ALT}<19$} & \multicolumn{2}{|c|}{$19 \leq \mathrm{ALT}<22$} & \multicolumn{2}{|c|}{$22 \leq A L T<27$} & \multicolumn{2}{|c|}{$27 \leq A L T \leq 35$} & P Value & \\
\hline $\mathbf{N}=$ & \multicolumn{2}{|c|}{767} & \multicolumn{2}{|c|}{652} & \multicolumn{2}{|c|}{607} & & 38 & & 25 & & \\
\hline Age (years) & 44 & (11) & 45 & $(11)$ & 45 & (11) & 45 & (11) & 45 & (11) & 0.703 & 0.369 \\
\hline Waist $(\mathrm{cm})$ & 82 & (12) & 82 & $(12)$ & 82 & (12) & 82 & (12) & 83 & (11) & 0.389 & 0.171 \\
\hline $\mathrm{BMI}\left(\mathrm{kg} / \mathrm{m}^{2}\right)$ & 25 & (5) & 25 & (5) & 25 & (5) & 25 & (5) & 26 & (5) & 0.489 & 0.248 \\
\hline
\end{tabular}


Table 1: Patient characteristics* according to quintiles of ALT (Continued)

\begin{tabular}{|c|c|c|c|c|c|c|c|c|c|c|c|c|}
\hline Diastolic BP (mmHg) & 73 & (8) & 74 & (8) & 74 & (8) & 74 & (9) & 74 & (8) & 0.209 & 0.019 \\
\hline Systolic BP (mmHg) & 117 & (15) & 117 & (16) & 117 & (15) & 117 & (16) & 118 & (16) & 0.688 & 0.420 \\
\hline Alcohol consumption (glasses/week) & 0.5 & (1.1) & 0.5 & $(1.1)$ & 0.5 & $(1.1)$ & 0.5 & $(1.2)$ & 0.5 & $(1.1)$ & 0.999 & 0.867 \\
\hline Exercise intensity (hours/week) & 1.9 & $(2.8)$ & 1.8 & $(2.5)$ & 2.0 & (3.4) & 1.7 & $(2.3)$ & 1.8 & $(2.4)$ & 0.474 & 0.329 \\
\hline Smoking status, n (\%) & & & & & & & & & & & 0.447 & \\
\hline Current & 150 & (19.9) & 129 & (20.3) & 99 & (16.6) & 136 & $(18.8)$ & 114 & $(18.7)$ & & \\
\hline Former & 145 & $(19.2)$ & 124 & (19.5) & 131 & (22.0) & 125 & $(17.3)$ & 126 & $(20.7)$ & & \\
\hline Hypertension, n (\%) & 106 & $(13.8)$ & 111 & $(17.0)$ & 89 & $(14.7)$ & 118 & $(16.0)$ & 101 & $(16.2)$ & 0.481 & \\
\hline Anti-hypertensive medications, $\mathrm{n}(\%)$ & 55 & $(7.2)$ & 56 & (8.6) & 46 & (7.6) & 52 & $(7.0)$ & 40 & $(6.4)$ & 0.648 & \\
\hline Metabolic Syndrome, n (\%) & 84 & $(11.0)$ & 102 & (15.6) & 106 & $(17.5)$ & 173 & $(23.4)$ & 180 & $(28.8)$ & $<0.001$ & \\
\hline Glucose (mmol/L) & 4.87 & $(0.48)$ & 4.95 & $(0.50)$ & 5.05 & $(0.53)$ & 5.12 & $(0.55)$ & 5.18 & $(0.55)$ & $<0.001$ & $<0.001$ \\
\hline HDL Cholesterol (mmol/L) & 1.60 & $(0.37)$ & 1.52 & $(0.40)$ & 1.48 & $(0.37)$ & 1.41 & $(0.35)$ & 1.35 & $(0.33)$ & $<0.001$ & $<0.001$ \\
\hline LDL Cholesterol (mmol/L) & 2.90 & $(0.80)$ & 3.02 & $(0.80)$ & 3.13 & $(0.79)$ & 3.19 & $(0.81)$ & 3.15 & $(0.85)$ & $<0.001$ & $<0.001$ \\
\hline Triglycerides $^{\dagger}(\mathrm{mmol} / \mathrm{L})$ & 0.93 & & 1.01 & & 1.06 & & 1.21 & & 1.29 & & $<0.001$ & $<0.001$ \\
\hline Statins, $n(\%)$ & 59 & (7.7) & 40 & $(6.1)$ & 48 & $(7.9)$ & 41 & (5.6) & 33 & $(5.3)$ & 0.164 & \\
\hline Fibrates, n(\%) & 6 & $(0.8)$ & 5 & $(0.8)$ & 5 & $(0.8)$ & 0 & (0) & 1 & $(0.2)$ & 0.073 & \\
\hline
\end{tabular}

* - Data are arithmetic means (S.D.) or N (\%).

t- Geometric means.

List of Abbreviations: ALT, alanine aminotransferase; BMI, body mass index; BP, blood pressure; HDL, high density lipoprotein; LDL, low density lipoprotein. 
Table 2: Patients characteristics* according to quintiles of GGT

\begin{tabular}{|c|c|c|c|c|c|c|c|c|c|c|c|c|}
\hline \multirow[t]{2}{*}{ Men $(\mathrm{N}=6561)$} & \multicolumn{2}{|c|}{$1^{\text {st }}$ Quintile } & \multicolumn{2}{|c|}{ 2nd Quintile } & \multicolumn{2}{|c|}{$3^{\text {rd }}$ Quintile } & \multicolumn{2}{|c|}{$4^{\text {th }}$ Quintile } & \multicolumn{2}{|c|}{$5^{\text {th }}$ Quintile } & \multirow{2}{*}{$\begin{array}{l}\text { ANOVA } \\
\text { P Value }\end{array}$} & \multirow{3}{*}{$\begin{array}{l}\mathrm{P} \text { for linear } \\
\text { trend }\end{array}$} \\
\hline & \multicolumn{2}{|c|}{ GGT $<9$} & \multicolumn{2}{|c|}{$9 \leq \mathrm{GGT}<12$} & \multicolumn{2}{|c|}{$12 \leq \mathrm{GGT}<16$} & \multicolumn{2}{|c|}{$16 \leq \mathrm{GGT}<21$} & \multicolumn{2}{|c|}{$21 \leq \mathrm{GGT} \leq 42$} & & \\
\hline $\mathbf{N}=$ & \multicolumn{2}{|c|}{1318} & \multicolumn{2}{|c|}{1206} & \multicolumn{2}{|c|}{1443} & \multicolumn{2}{|c|}{1202} & \multicolumn{2}{|c|}{1392} & & \\
\hline Age (years) & & (11) & 44 & $(11)$ & 44 & (11) & 44 & $(11)$ & 44 & (11) & 0.482 & 0.848 \\
\hline Waist (cm) & & (10) & 95 & (11) & 95 & (11) & 95 & $(10)$ & 95 & (11) & 0.721 & 0.165 \\
\hline BMI $\left(\mathrm{kg} / \mathrm{m}^{2}\right)$ & 27 & (4) & 27 & (4) & 27 & (4) & 27 & (4) & 27 & (4) & 0.875 & 0.433 \\
\hline Diastolic BP (mmHg) & 78 & (8) & 78 & (8) & 78 & (9) & 78 & (9) & 78 & (9) & 0.398 & 0.063 \\
\hline Systolic BP (mmHg) & 124 & (14) & 125 & (15) & 123 & (14) & 125 & (15) & 124 & (14) & 0.062 & 0.244 \\
\hline Alcohol consumption (glasses/week) & 1.1 & (1.6) & 1.0 & $(1.5)$ & 1.0 & $(1.5)$ & 1.1 & $(1.6)$ & 1.0 & $(1.6)$ & 0.458 & 0.466 \\
\hline Exercise intensity (hours/week) & 2.4 & $(2.9)$ & 2.2 & $(2.6)$ & 2.3 & $(2.8)$ & 2.2 & $(2.7)$ & 2.3 & $(2.5)$ & 0.327 & 0.254 \\
\hline Smoking status, n (\%) & & & & & & & & & & & 0.785 & \\
\hline Current & 205 & $(15.9)$ & 194 & $(16.3)$ & 217 & $(15.4)$ & 198 & $(16.8)$ & 225 & $(16.5)$ & & \\
\hline Former & 333 & (25.9) & 313 & $(26.4)$ & 368 & $(26.1)$ & 332 & $(28.1)$ & 344 & $(25.2)$ & & \\
\hline Hypertension, n (\%) & 301 & (22.8) & 298 & $(24.7)$ & 347 & $(24.0)$ & 329 & $(27.4)$ & 339 & $(24.4)$ & 0.113 & \\
\hline Anti-hypertensive medications, n(\%) & 120 & $(9.1)$ & 117 & $(9.7)$ & 131 & $(9.1)$ & 122 & $(10.1)$ & 141 & $(10.1)$ & 0.790 & \\
\hline Metabolic Syndrome, n (\%) & 79 & (6.0) & 145 & $(12.0)$ & 186 & $(12.9)$ & 227 & $(18.9)$ & 279 & $(20.0)$ & $<0.001$ & \\
\hline Glucose (mmol/L) & 4.87 & $(0.47)$ & 4.95 & $(0.49)$ & 5.06 & $(0.52)$ & 5.15 & $(0.54)$ & 5.20 & $(0.53)$ & $<0.001$ & $<0.001$ \\
\hline HDL Cholesterol (mmol/L) & 1.58 & $(0.39)$ & 1.48 & $(0.38)$ & 1.44 & $(0.34)$ & 1.39 & $(0.34)$ & 1.36 & $(0.32)$ & $<0.001$ & $<0.001$ \\
\hline LDL Cholesterol (mmol/L) & 2.93 & $(0.79)$ & 3.05 & $(0.83)$ & 3.11 & $(0.82)$ & 3.21 & $(0.82)$ & 3.21 & $(0.79)$ & $<0.001$ & $<0.001$ \\
\hline Triglycerides $^{\dagger}(\mathrm{mmol} / \mathrm{L})$ & 0.92 & & 1.02 & & 1.08 & & 1.23 & & 1.35 & & $<0.001$ & $<0.001$ \\
\hline Statins, $n(\%)$ & 111 & (8.4) & 95 & $(7.9)$ & 114 & (7.9) & 129 & $(10.7)$ & 160 & $(11.5)$ & 0.001 & \\
\hline Fibrates, $\mathrm{n}(\%)$ & 9 & $(0.7)$ & 13 & $(1.1)$ & 12 & $(0.8)$ & 20 & $(1.7)$ & 12 & $(0.9)$ & 0.116 & \\
\hline \multirow[t]{2}{*}{ Women ( $N=3389$ ) } & \multicolumn{2}{|c|}{$1^{\text {st }}$ Quintile } & \multicolumn{2}{|c|}{$2^{\text {nd }}$ Quintile } & \multicolumn{2}{|c|}{$3^{\text {rd }}$ Quintile } & \multicolumn{2}{|c|}{$4^{\text {th }}$ Quintile } & \multicolumn{2}{|c|}{$5^{\text {th }}$ Quintile } & ANOVA & $\begin{array}{l}\text { P for linear } \\
\text { trend }\end{array}$ \\
\hline & \multicolumn{2}{|c|}{$\mathrm{GGT}<8$} & \multicolumn{2}{|c|}{$8 \leq \mathrm{GGT}<11$} & \multicolumn{2}{|c|}{$11 \leq \mathrm{GGT}<15$} & \multicolumn{2}{|c|}{$15 \leq \mathrm{GGT}<19$} & \multicolumn{2}{|c|}{$19 \leq \mathrm{GGT} \leq 28$} & P Value & \\
\hline $\mathbf{N}=$ & & 86 & & 570 & & 346 & & 520 & & 67 & & \\
\hline Age (years) & 45 & (10) & 46 & (11) & 44 & (11) & 45 & $(10)$ & 44 & (11) & 0.001 & 0.013 \\
\hline Waist $(\mathrm{cm})$ & 81 & (11) & 83 & (12) & 82 & (12) & 83 & $(11)$ & 82 & (12) & 0.037 & 0.697 \\
\hline BMI $\left(\mathrm{kg} / \mathrm{m}^{2}\right)$ & 25 & (5) & 26 & (5) & 25 & (5) & 26 & (5) & 25 & (5) & 0.047 & 0.636 \\
\hline
\end{tabular}


Table 2: Patients characteristics* according to quintiles of GGT (Continued)

\begin{tabular}{|c|c|c|c|c|c|c|c|c|c|c|c|c|}
\hline Diastolic BP (mmHg) & 73 & (7) & 74 & (8) & 74 & (8) & 74 & (8) & 73 & (9) & 0.028 & 0.323 \\
\hline Systolic BP (mmHg) & 117 & (15) & 118 & (16) & 117 & (16) & 117 & (15) & 116 & (15) & 0.066 & 0.111 \\
\hline Alcohol consumption (glasses/week) & 0.4 & $(1.0)$ & 0.4 & $(1.0)$ & 0.5 & $(1.2)$ & 0.5 & $(1.1)$ & 0.6 & $(1.2)$ & 0.098 & 0.058 \\
\hline Exercise intensity (hours/week) & 1.8 & $(2.7)$ & 1.9 & $(2.6)$ & 1.9 & $(2.7)$ & 1.8 & (3.1) & 1.8 & $(2.3)$ & 0.869 & 0.802 \\
\hline Smoking status, $\mathrm{n}(\%)$ & & & & & & & & & & & 0.515 & \\
\hline Current & 107 & $(18.8)$ & 137 & (20.9) & 165 & $(19.9)$ & 106 & $(17.5)$ & 113 & $(17.2)$ & & \\
\hline Former & 105 & $(18.5)$ & 127 & (19.3) & 150 & $(18.1)$ & 130 & (21.5) & 139 & (21.1) & & \\
\hline Hypertension, n (\%) & 91 & $(15.5)$ & 117 & (17.5) & 127 & $(15.0)$ & 103 & (16.6) & 87 & (13.0) & 0.216 & \\
\hline Anti-hypertensive medications, n(\%) & 53 & $(9.0)$ & 51 & $(7.6)$ & 59 & $(7.0)$ & 51 & $(8.2)$ & 35 & $(5.2)$ & 0.101 & \\
\hline Metabolic Syndrome, n (\%) & 56 & (9.6) & 96 & $(14.3)$ & 158 & $(18.7)$ & 158 & (25.5) & 177 & (26.5) & $<0.001$ & \\
\hline Glucose (mmol/L) & 4.83 & $(0.48)$ & 4.96 & $(0.51)$ & 5.03 & $(0.53)$ & 5.15 & $(0.56)$ & 5.16 & $(0.54)$ & $<0.001$ & $<0.001$ \\
\hline HDL Cholesterol (mmol/L) & 1.63 & $(0.38)$ & 1.52 & $(0.38)$ & 1.46 & $(0.37)$ & 1.40 & $(0.34)$ & 1.40 & $(0.36)$ & $<0.001$ & $<0.001$ \\
\hline LDL Cholesterol (mmol/L) & 2.87 & $(0.77)$ & 3.03 & $(0.82)$ & 3.11 & $(0.78)$ & 3.20 & $(0.85)$ & 3.15 & $(0.83)$ & $<0.001$ & $<0.001$ \\
\hline Triglycerides $^{\dagger}(\mathrm{mmol} / \mathrm{L})$ & 0.90 & & 0.96 & & 1.10 & & 1.21 & & 1.31 & & $<0.001$ & $<0.001$ \\
\hline Statins, $\mathrm{n}(\%)$ & 40 & (6.8) & 58 & (8.7) & 43 & $(5.1)$ & 44 & $(7.1)$ & 36 & (5.4) & 0.046 & \\
\hline Fibrates, n(\%) & 4 & $(0.7)$ & 6 & $(0.9)$ & 2 & $(0.2)$ & 1 & $(0.2)$ & 4 & $(0.6)$ & 0.265 & \\
\hline
\end{tabular}

* - Data are arithmetic means (S.D.) or N (\%).

$\dagger$ - Geometric means.

List of abbreviations: GGT, gamma-glutamyl transferase; BMI, body mass index; BP, blood pressure; HDL, high density lipoprotein; LDL, low density lipoprotein. 
Table 3: Logistic regression analysis for the presence of MetS in relation ALT quintiles*.

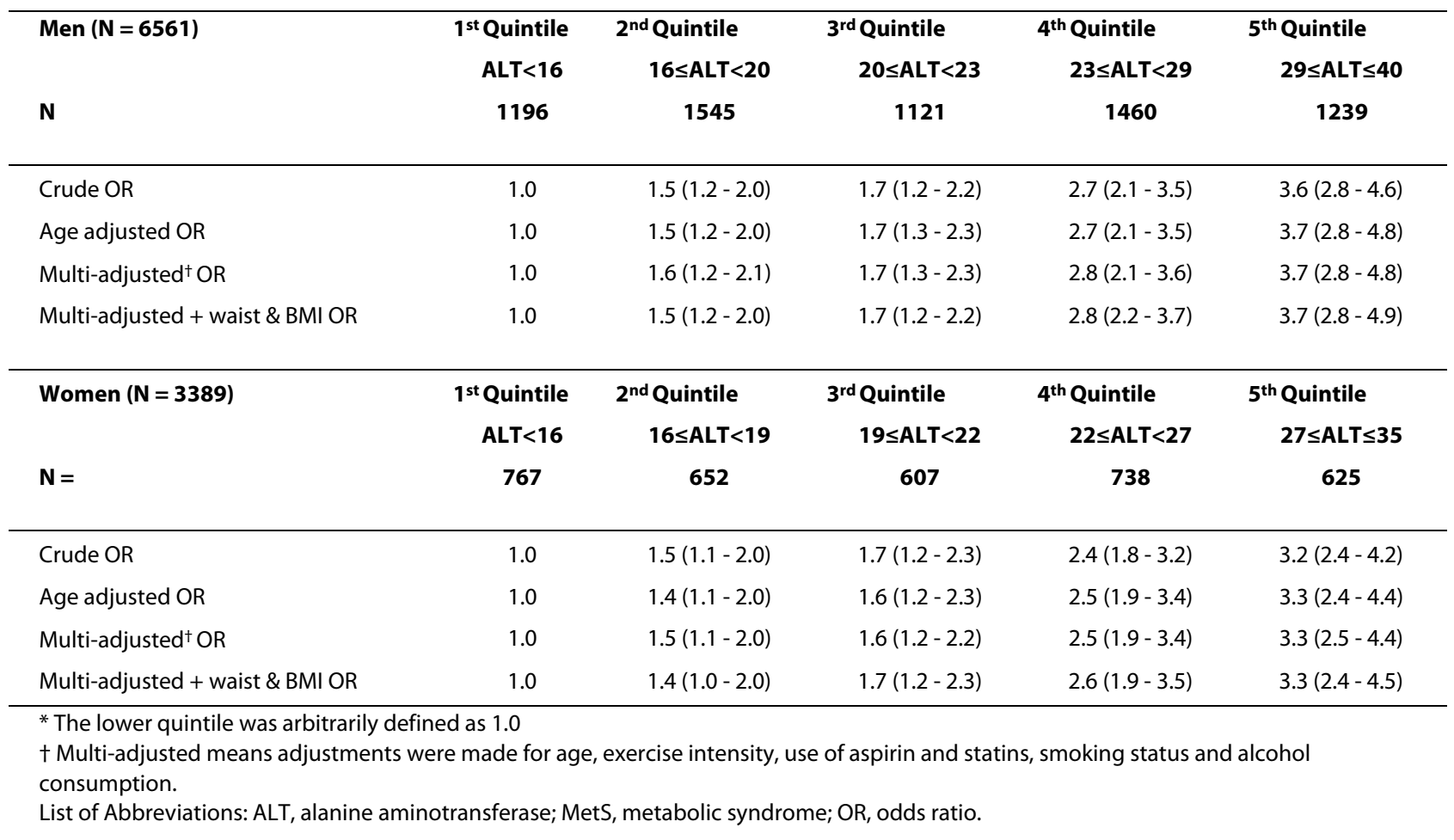

performed, would barely reveal the typical changes if at all. Therefore, quantitative analysis of liver enzymes remains the main diagnostic tool in this situation.

The present findings are not necessarily of solely theoretical relevance. In fact, the elevations in the concentrations of these liver enzymes might be contributory in the etiopathogenesis of the atherothrombotic inflammatory process. In particular, GGT might have an important role in the extracellular catabolism of glutathione, the principal thiol antioxidant in humans [14]. In addition, this enzyme has the ability to catalyze the oxidation of LDL-C [38] and may also be pro-inflammatory due to the fact that it mediates the interconversion of leukotriene $C 4$ into D4 [39]. As mentioned, GGT may directly take part in atherogenesis and evolve as a potential biochemical risk indicator of cardiovascular morbidity and mortality and thus have an application in primary and secondary prevention of cardiovascular disease [18]. Alanine aminotransferase however, is considered a more liver-specific marker than GGT. This is due to the fact that GGT is present on the surface of most cell types and is highly active in organs other than the liver [18]. Although both ALT and GGT have shown predictive for diabetes in a recent meta-analysis, GGT may be a better diabetes predictor than ALT [19]. In this regard, an increased enzyme level in the absence of known liver disease most commonly reflect liver fat deposition and is representative of the presence of visceral fat [21]. This visceral fat and obe- sity is central to the nuclear peroxisome proliferator activated receptors (PPAR) deactivation contributing to the development of insulin resistance, MetS and atherothrombosis $[40,41]$.

The notion that persistently elevated liver enzyme concentrations, even within the so-called "reference" range, is associated with cardiovascular risk factors and future disease has been previously demonstrated [42]. In fact, it has been shown that several liver enzymes, in particular GGT, are associated with the appearance of cardiovascular events [13]. This is also relevant to individuals with the MetS [14]. Thus, the recognition that the prevalence of the MetS increases even in individuals whose liver enzymes are in the lower part of the 'normal' reference range, might have clinical significance in terms of early recognition of these dysmetabolic changes.

We recognize several limitations in the current analysis. First, our conclusions are of a descriptive nature and are based essentially only on associations between parameters. Based upon its cross sectional design, the present findings are inherently limited in the ability to eliminate causal relationships. Second, since some of the study population had several risk factors, we could not fully eliminate the possible effect of underlying diseases and medications used for these diseases on the present findings. Further prospective population-based studies are needed to investigate the mechanisms in order to answer these questions. Finally, serum GGT is a sensitive indica- 
Table 4: Logistic regression analysis for the presence of MetS in relation GGT quintiles*.

\begin{tabular}{|c|c|c|c|c|c|}
\hline Men $(N=6561)$ & & & & & $5^{\text {th }}$ Quintile \\
\hline & GGT $<9$ & $9 \leq \mathrm{GGT}<12$ & $12 \leq \mathrm{GGT}<16$ & $16 \leq \mathrm{GGT}<21$ & $21 \leq \mathrm{GGT} \leq 42$ \\
\hline $\mathbf{N}=$ & 1318 & 1206 & 1443 & 1202 & 1392 \\
\hline Crude OR & 1.0 & $2.1(1.6-2.8)$ & $2.3(1.8-3.0)$ & $3.6(2.7-4.7)$ & $3.9(3.0-5.1)$ \\
\hline Age adjusted OR & 1.0 & $2.2(1.6-2.9)$ & $2.4(1.8-3.2)$ & $3.7(2.8-4.8)$ & $4.1(3.1-5.3)$ \\
\hline Multi-adjusted ${ }^{\dagger}$ OR & 1.0 & $2.2(1.6-2.9)$ & $2.4(1.8-3.2)$ & $3.7(2.8-4.8)$ & $4.1(3.1-5.3)$ \\
\hline Multi-adjusted + waist \& BMI OR & 1.0 & $2.3(1.7-3.0)$ & $2.5(1.9-3.3)$ & $4.0(3.0-5.3)$ & $4.5(3.4-5.9)$ \\
\hline \multirow[t]{2}{*}{ Women ( $N=3389)$} & $1^{\text {st }}$ Quintile & 2nd $^{\text {Quintile }}$ & $3^{\text {rd }}$ Quintile & $4^{\text {th }}$ Quintile & $5^{\text {th }}$ Quintile \\
\hline & $\mathbf{G G T}<\mathbf{8}$ & $8 \leq \mathbf{G G T}<11$ & $11 \leq \mathrm{GGT}<15$ & $15 \leq \mathrm{GGT}<19$ & $19 \leq \mathrm{GGT} \leq 28$ \\
\hline $\mathbf{N}=$ & 586 & 670 & 846 & 620 & 667 \\
\hline Crude OR & 1.0 & $1.6(1.1-2.3)$ & $2.2(1.6-3.0)$ & $3.2(2.3-4.4)$ & $3.4(2.5-4.7)$ \\
\hline Age adjusted OR & 1.0 & $1.5(1.1-2.2)$ & $2.3(1.7-3.3)$ & $3.3(2.4-4.7)$ & $3.9(2.8-5.4)$ \\
\hline Multi-adjusted ${ }^{\dagger}$ OR & 1.0 & $1.5(1.1-2.2)$ & $2.4(1.7-3.3)$ & $3.3(2.4-4.7)$ & $3.9(2.8-5.5)$ \\
\hline Multi-adjusted + waist \& BMI OR & 1.0 & $1.4(1.0-2.1)$ & $2.4(1.7-3.4)$ & $3.4(2.4-4.7)$ & $4.1(2.9-5.8)$ \\
\hline
\end{tabular}

* The lower quintile was arbitrarily defined as 1.0.

† Multi-adjusted means adjustments were made for age, exercise intensity, use of aspirin and statins, smoking status and alcohol consumption.

List of abbreviations: GGT, gamma-glutamyl transferase; MetS, metabolic syndrome; OR, odds ratio.

tor of alcohol consumption and/or liver dysfunction such as fatty liver, and is also high in patients with liver disease: chronic viral hepatitis, primary biliary cirrhosis, or druginduced liver injury. These liver diseases are present in community-dwelling persons and are usually asymptomatic. Thus, these possible confounders could have affected results.

We conclude that a relatively high prevalence of the MetS has been noted in a cohort of apparently healthy individuals who have within-normal-limits concentrations of liver enzymes. The relatively high prevalence of the MetS observed could explain, at least in part, the previously noted epidemiological associations between elevated concentrations of GGT and ALT and future vascular risk. Moreover, our findings suggest that even minute changes, still within the so called "normal range" could point towards a potential dysmetabolic state. These observations could therefore lead to avoiding the usage of cut-off values for normalcy for these two biomarkers. In addition, they should encourage the use of both GGT and ALT as continuous biomarkers that could be used for early signaling of dysmetabolism. Finally, our results support the notion that in the era of early detection, prevention and treatment of metabolic disorders, one cannot be confident that relatively low concentrations of liver enzymes exclude the presence of dysmetabolic changes. A practical consequence might therefore be to follow these enzyme concentrations as continuous biomarkers and take into consideration the possibility that even small changes in their concentrations might be of relevance.

\section{Declaration of competing interests}

The authors declare that they have no competing interests.

\section{Authors' contributions}

OR and AS have participated in the design of the study, performed the statistical analyses and drafted the paper. SB and IS conceived the study, participated in its design and coordination and helped to draft and review the manuscript. $\mathrm{OKB}, \mathrm{MC}$ and $\mathrm{YV}$ helped in the data organization and retrieval, English editing and final draft preparation. All of the authors have read and approved the final manuscript.

\section{Acknowledgements}

none.

\section{Author Details}

'Departments of Medicine "D" \& "E", The Tel-Aviv Sourasky Medical Center, 6 Weizman St, Tel Aviv, 64239, Israel and 2the Central Laboratory of the Tel Aviv Sourasky Medical Center, affiliated to the Sackler Faculty of Medicine, Tel Aviv University, Tel Aviv, Israel

Received: 7 June 2010 Accepted: 15 July 2010

Published: 15 July 2010

\section{References}

1. Dekker JM, Girman C, Rhodes T, Nijpels G, Stehouwer CD, Bouter LM, Heine RJ: Metabolic syndrome and 10-year cardiovascular disease risk in the Hoorn Study. Circulation 2005, 112:666-673.

2. Jeppesen J, Hansen TW, Rasmussen S, Ibsen H, Torp-Pedersen C, Madsbad $S$ : Insulin resistance, the metabolic syndrome, and risk of incident cardiovascular disease: a population-based study. J Am Coll Cardiol 2007, 49:2112-2119. 
3. Lakka HM, Laaksonen DE, Lakka TA, Niskanen LK, Kumpusalo E, Tuomilehto J, Salonen JT: The metabolic syndrome and total and cardiovascular disease mortality in middle-aged men. Jama 2002, 288:2709-2716.

4. Malik S, Wong ND, Franklin SS, Kamath TV, L'Italien GJ, Pio JR, Williams GR Impact of the metabolic syndrome on mortality from coronary heart disease, cardiovascular disease, and all causes in United States adults. Circulation 2004, 110:1245-1250.

5. Devers MC, Campbell S, Shaw J, Zimmet P, Simmons D: Should liver function tests be included in definitions of metabolic syndrome? Evidence from the association between liver function tests, components of metabolic syndrome and prevalent cardiovascular disease. Diabet Med 2008, 25:523-529.

6. Andre P, Balkau B, Vol S, Charles MA, Eschwege E: Gammaglutamyltransferase activity and development of the metabolic syndrome (International Diabetes Federation Definition) in middleaged men and women: Data from the Epidemiological Study on the Insulin Resistance Syndrome (DESIR) cohort. Diabetes Care 2007, 30:2355-2361

7. Nannipieri M, Gonzales C, Baldi S, Posadas R, Williams K, Haffner SM, Stern MP, Ferrannini E: Liver enzymes, the metabolic syndrome, and incident diabetes: the Mexico City diabetes study. Diabetes Care 2005, 28:1757-1762.

8. Hanley AJ, Williams K, Festa A, Wagenknecht LE, D'Agostino RB Jr, Haffne SM: Liver markers and development of the metabolic syndrome: the insulin resistance atherosclerosis study. Diabetes 2005, 54:3140-3147.

9. Liangpunsakul S, Chalasani N: Unexplained elevations in alanine aminotransferase in individuals with the metabolic syndrome: results from the third National Health and Nutrition Survey (NHANES III). Am J Med Sci 2005, 329:111-116.

10. Goessling W, Massaro JM, Vasan RS, D'Agostino RB Sr, Ellison RC, Fox CS: Aminotransferase Levels and 20-Year Risk of Metabolic Syndrome, Diabetes, and Cardiovascular Disease. Gastroenterology 2008, 135(6):1935-44. 1944.e

11. Emdin M, Passino C, Michelassi C, Titta F, L'Abbate A, Donato L, Pompella A, Paolicchi A: Prognostic value of serum gamma-glutamyl transferase activity after myocardial infarction. Eur Heart J 2001, 22:1802-1807.

12. Jousilahti $P$, Rastenyte $D$, Tuomilehto J: Serum gamma-glutamyl transferase, self-reported alcohol drinking, and the risk of stroke. Stroke 2000, 31:1851-1855.

13. Lee DH, Silventoinen $K, H u$ G, Jacobs DR Jr, Jousilahti P, Sundvall J, Tuomilehto J: Serum gamma-glutamyltransferase predicts non-fatal myocardial infarction and fatal coronary heart disease among 28,838 middle-aged men and women. Eur Heart J 2006, 27:2170-2176.

14. Lee DS, Evans JC, Robins SJ, Wilson PW, Albano I, Fox CS, Wang TJ, Benjamin EJ, D'Agostino RB, Vasan RS: Gamma glutamyl transferase and metabolic syndrome, cardiovascular disease, and mortality risk: the Framingham Heart Study. Arterioscler Thromb Vasc Biol 2007, 27:127-133.

15. Meisinger C, Doring A, Schneider A, Lowel H: Serum gammaglutamyltransferase is a predictor of incident coronary events in apparently healthy men from the general population. Atherosclerosis 2006, 189:297-302.

16. Ruttmann E, Brant LJ, Concin H, Diem G, Rapp K, Ulmer H: Gammaglutamyltransferase as a risk factor for cardiovascular disease mortality: an epidemiological investigation in a cohort of 163,944 Austrian adults. Circulation 2005, 112:2130-2137.

17. Wannamethee G, Ebrahim S, Shaper AG: Gamma-glutamyltransferase: determinants and association with mortality from ischemic heart disease and all causes. Am J Epidemiol 1995, 142:699-708.

18. Turgut O, Yilmaz A, Yalta K, Karadas F, Birhan Yilmaz M: gammaGlutamyltransferase is a promising biomarker for cardiovascular risk. Medical hypotheses 2006, 67:1060-1064

19. Fraser A, Harris R, Sattar N, Ebrahim S, Davey Smith G, Lawlor DA: Alanine aminotransferase, gamma-glutamyltransferase, and incident diabetes: the British Women's Heart and Health Study and meta-analysis. Diabetes Care 2009, 32:741-750.

20. Ekstedt M, Franzen LE, Mathiesen UL, Thorelius L, Holmqvist M, Bodemar $G$, Kechagias S: Long-term follow-up of patients with NAFLD and elevated liver enzymes. Hepatology 2006, 44:865-873.

21. Kain K, Carter AM, Grant PJ, Scott EM: Alanine aminotransferase is associated with atherothrombotic risk factors in a British South Asian population. J Thromb Haemost 2008, 6:737-741.
22. Sattar N, Scherbakova O, Ford I, O'Reilly DS, Stanley A, Forrest E, Macfarlane PW, Packard CJ, Cobbe SM, Shepherd J: Elevated alanine aminotransferase predicts new-onset type 2 diabetes independently of classical risk factors, metabolic syndrome, and C-reactive protein in the west of Scotland coronary prevention study. Diabetes 2004, 53:2855-2860.

23. Steinvil A, Berliner S, Bromberg M, Cohen M, Shalev V, Shapira I, Rogowski $\mathrm{O}$ : Micro-inflammatory changes in asymptomatic healthy adults during bouts of respiratory tract infections in the community: potential triggers for atherothrombotic events. Atherosclerosis 2009 206:270-275.

24. Rogowski O, Steinvil A, Berliner S, Cohen M, Saar N, Ben-Bassat OK, Shapira I: Elevated resting heart rate is associated with the metabolic syndrome. Cardiovasc Diabeto/ 2009, 8:55

25. Rogowski O, Shapira I, Steinvil A, Berliner S: Low-grade inflammation in individuals with the hypertriglyceridemic waist phenotype: another feature of the atherogenic dysmetabolism. Metabolism 2009, 58:661-667.

26. Rogowski O, Shapira I, Peretz H, Berliner S: Glycohaemoglobin as a determinant of increased fibrinogen concentrations and low-grade inflammation in apparently healthy nondiabetic individuals. Clin Endocrinol (Oxf) 2008, 68:182-189.

27. Rogowski O, Shapira I, Shirom A, Melamed S, Toker S, Berliner S: Heart rate and microinflammation in men: a relevant atherothrombotic link. Heart 2007, 93:940-944.

28. Rogowski O, Toker S, Shapira I, Melamed S, Shirom A, Zeltser D, Berliner S Values of high-sensitivity C-reactive protein in each month of the year in apparently healthy individuals. Am J Cardiol 2005, 95:152-155.

29. Steinvil A, Shirom A, Melamed S, Toker S, Justo D, Saar N, Shapira I, Berliner S, Rogowski O: Relation of educational level to inflammation-sensitive biomarker level. Am J Cardio/ 2008, 102:1034-1039.

30. Executive Summary of The Third Report of The National Cholesterol Education Program (NCEP) Expert Panel on Detection, Evaluation, And Treatment of High Blood Cholesterol In Adults (Adult Treatment Panel III). Jama 2001, 285:2486-2497.

31. Alberti KG, Eckel RH, Grundy SM, Zimmet PZ, Cleeman JI, Donato KA Fruchart JC, James WP, Loria CM, Smith SC Jr: Harmonizing the metabolic syndrome: a joint interim statement of the International Diabetes Federation Task Force on Epidemiology and Prevention; National Heart, Lung, and Blood Institute; American Heart Association; World Heart Federation; International Atherosclerosis Society; and International Association for the Study of Obesity. Circulation 2009, 120:1640-1645.

32. Barham D, Trinder $P$ : An improved colour reagent for the determination of blood glucose by the oxidase system. Analyst 1972, 97:142-145.

33. Fossati $P$, Prencipe $L$ : Serum triglycerides determined colorimetrically with an enzyme that produces hydrogen peroxide. Clin Chem 1982 28:2077-2080

34. Izawa S, Okada M, Matsui H, Hotta Y, Hama H: A new direct method for measuring HDL-cholesterol which does not produce any biased values. Jpn J Med Pharm Sci 1997, 37:1385-1388.

35. Szasz G: Reaction-rate method for gamma-glutamyltransferase activity in serum. Clin Chem 1976, 22:2051-2055.

36. Bergmeyer HU, Horder M: International federation of clinical chemistry. Scientific committee. Expert panel on enzymes. IFCC document stage 2 , draft 1; 1979-11-19 with a view to an IFCC recommendation. IFCC methods for the measurement of catalytic concentration of enzymes. Part 3. IFCC method for alanine aminotransferase. J Clin Chem Clin Biochem 1980, 18:521-534.

37. Kotronen A, Westerbacka J, Bergholm R, Pietilainen $\mathrm{KH}$, Yki-Jarvinen $\mathrm{H}$ : Liver fat in the metabolic syndrome. J Clin Endocrinol Metab 2007, 92:3490-3497.

38. Paolicchi A, Emdin M, Passino C, Lorenzini E, Titta F, Marchi S, Malvaldi G, Pompella A: Beta-lipoprotein- and LDL-associated serum gammaglutamyltransferase in patients with coronary atherosclerosis. Atherosclerosis 2006, 186:80-85.

39. Anderson ME, Allison RD, Meister A: Interconversion of leukotrienes catalyzed by purified gamma-glutamyl transpeptidase: concomitant formation of leukotriene D4 and gamma-glutamyl amino acids. Proc Natl Acad Sci USA 1982, 79:1088-1091.

40. Despres JP, Lemieux I, Bergeron J, Pibarot P, Mathieu P, Larose E, RodesCabau J, Bertrand OF, Poirier P: Abdominal obesity and the metabolic 
syndrome: contribution to global cardiometabolic risk. Arterioscler Thromb Vasc Biol 2008, 28:1039-1049.

41. Tenenbaum A, Fisman EZ, Motro M: Metabolic syndrome and type 2 diabetes mellitus: focus on peroxisome proliferator activated receptors (PPAR). Cardiovascular diabetology 2003, 2:4.

42. Patel DA, Srinivasan SR, Xu JH, Chen W, Berenson GS: Persistent elevation of liver function enzymes within the reference range is associated with increased cardiovascular risk in young adults: the Bogalusa Heart Study. Metabolism 2007, 56:792-798.

doi: $10.1186 / 1475-2840-9-30$

Cite this article as: Steinvil et al., The association of higher levels of withinnormal-limits liver enzymes and the prevalence of the metabolic syndrome Cardiovascular Diabetology 2010, 9:30

Submit your next manuscript to BioMed Central and take full advantage of:

- Convenient online submission

- Thorough peer review

- No space constraints or color figure charges

- Immediate publication on acceptance

- Inclusion in PubMed, CAS, Scopus and Google Scholar

- Research which is freely available for redistribution

Submit your manuscript at www.biomedcentral.com/submit
C) Biomed Central 